\title{
The effectiveness of antenatal care programmes to reduce infant mortality and preterm birth in socially disadvantaged and vulnerable women in high-income countries: a systematic review
}

\author{
Jennifer Hollowell,' Laura Oakley, Jennifer J Kurinczuk, Peter Brocklehurst, Ron Gray
}

\begin{abstract}
Background: Infant mortality has shown a steady decline in recent years but a marked socioeconomic gradient persists. Antenatal care is generally thought to be an effective method of improving pregnancy outcomes, but the effectiveness of specific antenatal care programmes as a means of reducing infant mortality in socioeconomically disadvantaged and vulnerable groups of women has not been rigorously evaluated.

Methods: We conducted a systematic review, focusing on evidence from high income countries, to evaluate the effectiveness of alternative models of organising or delivering antenatal care to disadvantaged and vulnerable groups of women vs. standard antenatal care. We searched Medline, Embase, Cinahl, PsychINFO, HMIC, CENTRAL, DARE, MIDIRS and a number of online resources to identify relevant randomised and observational studies. We assessed effects on infant mortality and its major medical causes (preterm birth, congenital anomalies and sudden infant death syndrome (SIDS)).
\end{abstract}

Results: We identified 36 distinct eligible studies covering a wide range of interventions, including group antenatal care, clinic-based augmented care, teenage clinics, prenatal substance abuse programmes, home visiting programmes, maternal care coordination and nutritional programmes. Fifteen studies had adequate internal validity: of these, only one was considered to demonstrate a beneficial effect on an outcome of interest. Six interventions were considered 'promising'.

Conclusions: There was insufficient evidence of adequate quality to recommend routine implementation of any of the programmes as a means of reducing infant mortality in disadvantaged/vulnerable women. Several

interventions merit further more rigorous evaluation.

\section{Background}

In recent years, infant mortality in most parts of the world has shown a steady decline [1]. Across highincome OECD countries as a whole, the average infant mortality rate declined from 12.2 deaths per 1000 live births in 1980 to 4.9 deaths per 1000 live births in 2008; and in the United Kingdom the rate showed a similar decline, from 12.1 deaths per 1000 live births in 1980 to 4.9 deaths per 1000 live births in 2008. But throughout this period infant mortality has shown marked and

\footnotetext{
* Correspondence: jennifer.hollowell@npeu.ox.ac.uk

National Perinatal Epidemiology Unit, University of Oxford, Old Road
} Campus, Oxford, OX3 7LF, UK persistent socioeconomic gradients within countries, even in countries with universal healthcare access [2-4]. Immaturity related conditions and congenital anomalies are the two main causes of infant deaths in high-income countries [5-7]; and for both of these causes mortality rates exhibit socioeconomic gradients with the highest rates occurring in the most socioeconomically disadvantaged groups [8,9]. A number of so-called vulnerable groups also suffer disproportionately high rates of infant mortality (and other adverse perinatal outcomes), or have a high prevalence of risk factors for poor pregnancy outcome/infant health: such groups include teenagers [5,10], many black and minority ethnic groups $[10,11]$, homeless

\section{Biomed Central}


women [12,13], prisoners [12,14], women who have experienced domestic violence [15], asylum seekers and refugees [12], women with mental illness [16] and women with substance abuse problems $[12,17,18]$.

A review of the international effectiveness literature conducted at the NPEU in 2008 (updated in 2009 [19]) confirmed the paucity of relevant systematic review level evidence relating to infant mortality and related outcomes in disadvantaged populations; and a review of UK interventions to improve perinatal outcomes in disadvantaged groups found limited UK evidence of effective interventions for disadvantaged childbearing women [12].

Antenatal care is generally thought to be an effective method of improving outcomes in pregnant women and their babies, although many antenatal care practices have not been subject to rigorous evaluation [20]. One review from the early $1990 \mathrm{~s}$ evaluated 'prenatal care packages' [21] but found only five studies of adequate quality which evaluated the effect of the programme on gestational age at birth and/or infant mortality, two of which (Nurse Home Visitation [22]; and case management [23]) were found to have a positive effect on the relevant outcome measure.

Other systematic reviews have evaluated the effect of specific antenatal care packages on preterm birth (PTB) and infant mortality, including: alternative ways of delivering antenatal care to Australian indigenous women [24]; telephone support and home visiting programmes $[25,26]$; continuity of caregiver during pregnancy and childbirth $[27,28]$; and modified timing and frequency of antenatal care visits [29-31].

These reviews found that telephone support [25], home visits/social support $[25,26]$ and continuity of care $[27,28]$ had beneficial effects on a range of measures of maternal and infant health and wellbeing, but none of these interventions was found to have a statistically significant effect on infant mortality or PTB. One review [24] found some studies that reported beneficial effects of some interventions targeting Australian indigenous women, but the authors of the review concluded that the evidence was flawed.

In the light of the paucity of up to date evidence relating to the effectiveness of antenatal care programmes as a means of reducing infant mortality in disadvantaged groups of women, the aim of this systematic review was to identify the best available evidence on the effectiveness of interventions focused on the delivery and organisation of antenatal care to reduce infant mortality, or one of its three major causes (PTB, congenital anomalies, sudden infant death syndrome/sudden unexpected death in infancy (SIDS/SUDI)) in socially disadvantaged and vulnerable groups of women and other specific groups, such as teenagers and substance abusers, with risk factors for adverse birth outcomes strongly associated with social disadvantage.

\section{Methods}

Because the review findings were aimed at policy makers and healthcare managers, our approach incorporated some of the iterative methods of interpretive synthesis proposed by Lomas and others for policy research synthesis[32]: the research question, PICO criteria and methods for the identification and screening of studies were pre-specified but decisions regarding how best to analyse and present findings from the included studies were taken iteratively by the authors in the light of the available material.

\section{Criteria for including studies in the review}

Criteria for including studies in the review are summarised in Table 1.

\section{Methods for identification of studies}

We searched the following databases in mid-August 2008 for reports of primary research studies published between January 1990 and July 2008: Medline, Embase, Cinahl, PsycINFO, HMIC, CENTRAL, Database of Abstracts of Reviews of Effects (DARE), MIDIRS. We used a search strategy which combined MeSH terms/keyword and text search terms relating to the outcomes, interventions and populations of interest (See additional file 1).

We additionally searched a number of other specialist databases, including the Cochrane Database of Systematic Reviews, and online resources (see additional file 1 for list) to identify potentially eligible primary reports and also review articles, guidelines, and other reports that might contain relevant citations. The bibliographies of the latter were inspected to identify relevant primary reports.

Two reviewers independently assessed titles/abstracts of all potentially relevant/eligible references using a simple checklist of exclusion criteria. The full-text of articles not excluded on title/abstract was screened independently by two reviewers using a more detailed checklist of exclusion and inclusion criteria. At both stages, discrepancies were discussed and the opinion of a third reviewer sought where necessary to reach a final decision regarding eligibility.

\section{Quality assessment}

Internal validity was assessed using the 'Graphical appraisal tool for epidemiological studies' (GATE) developed by Jackson and colleagues [33]. GATE is a generic quality appraisal tool which can be applied to a wide range of experimental and observational study designs [34] and thus avoided the need to use different tools according to the study design. 
Table 1 Criteria for including studies in the review

\begin{tabular}{|c|c|}
\hline & Inclusion criteria \\
\hline Study design & Experimental or observational effectiveness evaluation, with control or comparator group \\
\hline \multirow[t]{2}{*}{ Population } & Socially disadvantaged or vulnerable populations* \\
\hline & $\begin{array}{l}\text { Other specified at risk population: teenagers, obese pregnant women, substance users, alcohol misusers, women who are HIV } \\
\text { positive }\end{array}$ \\
\hline \multirow[t]{10}{*}{ Intervention } & Intervention involving the organisation and/or delivery of: \\
\hline & - comprehensive antenatal care \\
\hline & - components of antenatal care provided in the context of normal antenatal care \\
\hline & and/or \\
\hline & $\begin{array}{l}\text { - Stand alone interventions involving the provision of health or social care to pregnant women delivered as an adjunct to } \\
\text { normal antenatal care }\end{array}$ \\
\hline & Exclusions: \\
\hline & $\begin{array}{l}\text { - stand-alone interventions targeting pregnant women not delivered and/or evaluated in conjunction with standard antenatal } \\
\text { care }\end{array}$ \\
\hline & - clinical interventions, unless evaluated in the context of a broader package of antenatal care \\
\hline & - interventions with a focus on labour/birth or the periconceptional period \\
\hline & - interventions involving only opiate substitution \\
\hline Comparator & Standard antenatal care or a specified alternative model of antenatal care \\
\hline \multirow[t]{4}{*}{ Outcome } & $\begin{array}{l}\text { - Preterm birth (or "preterm labour") expressed as the number/proportion of women delivering before } 37 \text { weeks gestation (or } \\
\text { some other cut-off point <37 weeks) }\end{array}$ \\
\hline & - Any measure of neonatal/infant mortality, but excluding perinatal mortality \\
\hline & - Birth prevalence of congenital anomalies \\
\hline & - SIDS/SUDI \\
\hline $\begin{array}{l}\text { Type of } \\
\text { publication }\end{array}$ & Journal articles reporting primary research in English and non-English language journal articles with an English Language abstract \\
\hline $\begin{array}{l}\text { Geographical } \\
\text { area }\end{array}$ & OECD member countries, excluding Mexico and Turkey** \\
\hline Time period & Published 1990 onwards \\
\hline
\end{tabular}

*Including: women living in deprived areas, disadvantaged minority ethnic/racial groups, women in prison, travellers, homeless women, asylum seekers and refugees, recently arrived migrants/other immigrant groups, victims of abuse, women with mental illness/mental health problems, women with learning disabilities, sex workers.

**High-income countries with low infant mortality.

Randomised studies were assessed by a single reviewer; observational studies were assessed independently by two reviewers. Each reviewer completed the checklist and assigned an overall assessment of internal validity according to the GATE criteria. Where the two assessments (observational studies only) differed, a third reviewer re-assessed the studies and a final rating was assigned following review and discussion of the three independently completed checklists. Risk of bias was assessed at the outcome level (PTB or infant mortality); where both PTB and infant mortality were reported, the assessment was based on the outcome considered to be the 'primary outcome'.

Prior to undertaking the study GATE assessments, reviewers completed and discussed a minimum of five 'training assessments' to ensure that the tool was being correctly and consistently applied.

\section{Data extraction}

A data extraction and coding form was developed and loaded into specialist review software (Eppi-Reviewer[35]).
Descriptive data were extracted and entered by one reviewer and checked by a second reviewer. Outcome data were extracted and coded/entered independently by two reviewers and checked for agreement.

\section{Assessment of evidence of effectiveness}

Two reviewers independently assessed and coded the authors' conclusions regarding the effect of the intervention on the outcomes of interest. For each of the outcomes reported, conclusions were coded as follows: (a) statistically significant effect on the outcome; (b) effect consistent with a beneficial effect but effect not statistically significant and/or cautious interpretation of findings recommended; (c) no evidence of beneficial effect; (d) no conclusion stated.

For studies having 'adequate' internal validity ('good' or 'mixed' GATE quality assessment), the reviewers also independently assessed and coded the evidence of effectiveness for individual outcomes, taking into account the strength and limitations noted in the GATE checklist. Evidence of effectiveness was coded as follows: (a) study 
demonstrates a beneficial effect on the outcome; (b) study inconclusive but suggestive of a beneficial effect; (c) study does not provide convincing evidence of a beneficial effect.

Discrepancies in coding were resolved by discussion with a third reviewer.

\section{Results}

\section{Studies included}

Our initial searches identified 3736 unique citations. Of these, 3597 were excluded on title/abstract alone and a further 103 were excluded following full-text review. (See additional file 2 for reasons for exclusion.) Four new articles were identified from reference lists and citations. In total, 40 eligible articles were included (see Figure 1) relating to 36 distinct interventions and/or studies. Two of the four 'secondary' reports, did not provide additional relevant data [36,37] (and are not considered further); and two provided additional data supplementing those provided in the 'primary' reports (one reported additional data on neonatal mortality [38] and one reported effectiveness data for a subgroup of interest [39]).

The characteristics of the 36 included primary studies are shown in Table 2.

\section{Outcomes evaluated}

All included studies reported PTB/preterm labour and/ or a measure of neonatal/infant mortality as an outcome (Table 2). Six studies [40-45] additionally reported congenital anomalies: this outcome is not considered further in this review because the low event rate, small combined sample size across studies and diversity of interventions meant that no conclusions could be drawn regarding intervention effects on this outcome. None of the included studies evaluated effects on SIDS/SUDI.

\section{Quality of evidence}

Eight of the nine included randomised controlled trials (RCTs) were assessed as having 'adequate' ('good' or 'mixed') internal validity, and one was rated 'poor'. Of the 27 primary observational studies, six were assessed as having 'adequate' internal validity (none 'good'; 6 'mixed') and 21 as 'poor' (See additional file 3).

Overall, fifteen of the studies (14 primary studies [23,41-43,46-55] and one secondary report providing supplementary data[38]) were considered to have 'adequate' internal validity.

\section{Interventions}

Twenty studies related to interventions targeting and/or evaluated in socioeconomically disadvantaged/deprived populations of which eight were aimed specifically at disadvantaged women with additional clinical risk factors for PTB or LBW. Seventeen of these studies were conducted in the USA, with most targeting medically indigent and/or Medicaid eligible women.

The other sixteen primary studies related to interventions targeting or evaluated in specific vulnerable population: nine targeted pregnant teenagers, four targeted pregnant substance users, two targeted pregnant indigenous Australians, and one intervention targeted pregnant women who were HIV positive. One further secondary report [38] provided data on the effectiveness of the latter intervention in a sub-group of substance using, HIV positive women.

Twenty-three of the studies evaluated alternative of models of delivering comprehensive antenatal care and 13 evaluated interventions provided as an adjunct to comprehensive antenatal care, including home visiting, nutritional programmes, case management/care coordination and substance abuse programmes provided alongside standard antenatal care. An overview of the intervention characteristics by target population is given in additional file 4. A more detailed description of the interventions is available elsewhere [19].

The fifteen studies assessed as having adequate internal validity are described in Tables 3 and 4 .

\section{Effectiveness}

\section{Comprehensive antenatal care programmes}

Eight studies of adequate quality evaluated comprehensive antenatal care programmes. Results are summarized in Table 5.

a) Programmes targeting socioeconomically disadvantaged women without specific clinical risk factors for PTB/LBW

Two linked studies reported by Ickovics $[49,50]$ evaluated the group antenatal care model in disadvantaged populations: the first an observational study conducted in clinics serving low-income, predominantly minority women in Atlanta, Georgia and New Haven, and the second a larger RCT conducted at university-affiliated hospitals in Connecticut and Georgia. The initial evaluation was inconclusive, largely because of the potential risk of selection bias. The subsequent trial reported a significant reduction in $\mathrm{PTB}$ in the group care arm (adjusted odds ratio $0.67,95 \%$ confidence interval (CI) 0.44-0.98).

An observational evaluation of the Temple Infant and Parent Support Services (TIPPS) programme [54], a 'customised' comprehensive multidisciplinary service designed to meet the specific needs of the local population in North Philadelphia, Pennsylvania, reported a statistically significant effect on PTB (4.3\% vs. $12 \%$ preterm in those not enrolled in TIPPS). Because of the risk of selection bias the reviewers considered the findings inconclusive but consistent with a possible beneficial effect. 


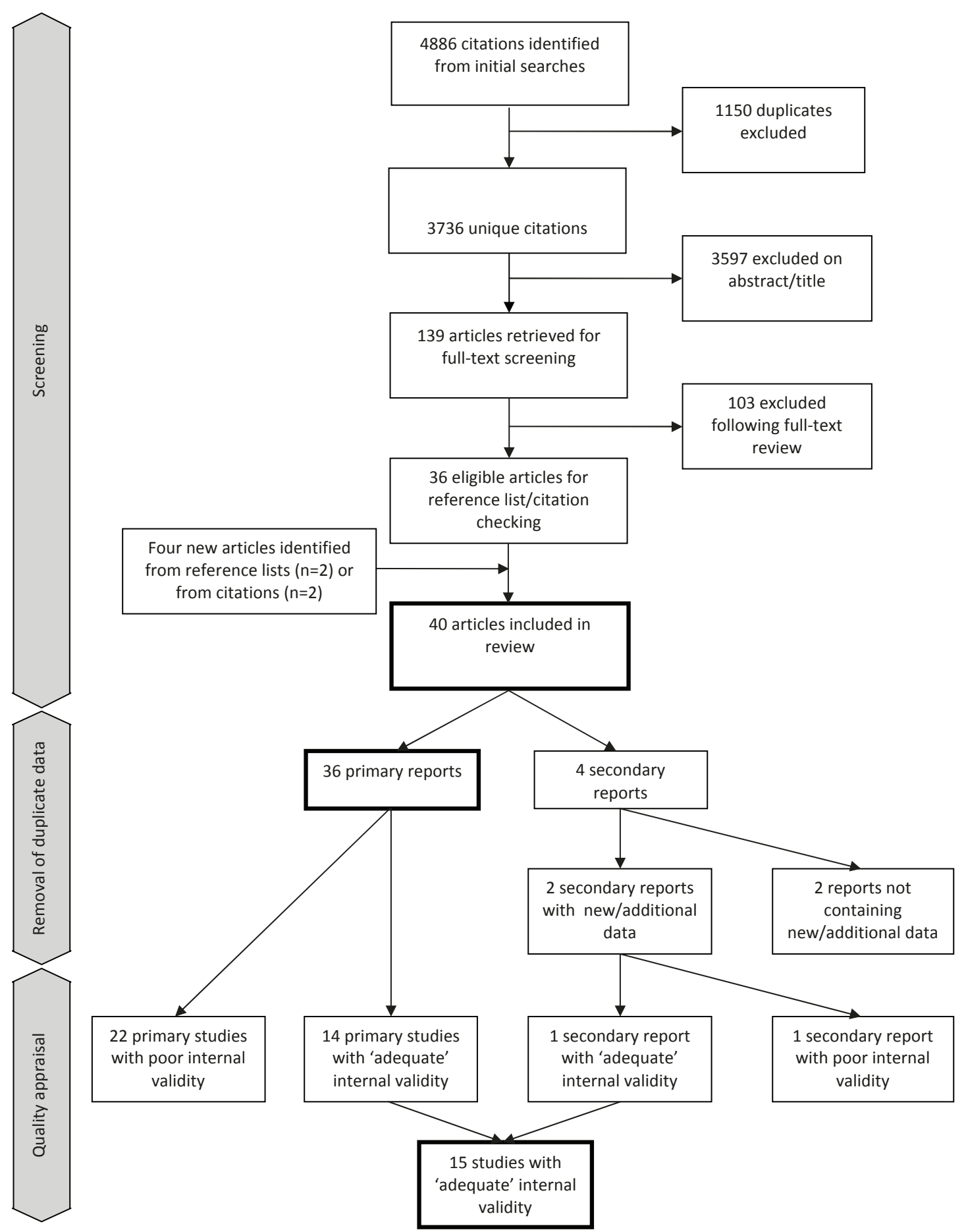

Figure 1 Screening and study inclusion flow chart.

One study, a before and after study with a contemporaneous comparison group, evaluated a 'managed care' model of delivering antenatal care (the Tennessee Medicaid Managed Care programme (TennCare)) in one US state (Tennessee) against a standard antenatal care model in an adjacent state (North Carolina) [47].
Outcomes (PTB and infant mortality) in the before and after periods did not show any relative improvement in the intervention area compared with the 'control' area. The study did not provide evidence of a beneficial effect of managed care on either PTB or neonatal mortality although some implementation problems occurred 
Table 2 Characteristics of the included primary studies

\begin{tabular}{lc}
\hline & Number (\%) of studies \\
\hline Year of publication & $8(22)$ \\
$1990-1994$ & $9(25)$ \\
$1995-1999$ & $15(42)$ \\
$2000-2004$ & $4(11)$ \\
$2005-2008$ (part year) & \\
Country & \\
USA & $26(72)$ \\
Australia & $4(11)$ \\
U.K. & $4(11)$ \\
Canada & $1(3)$ \\
Greece & $1(3)$ \\
& \\
Study design & \\
RCT-individually randomized & $7(19)$ \\
RCT-cluster randomized & $2(6)$ \\
Retrospective cohort study & $12(33)$ \\
Prospective cohort study & $6(17)$ \\
Cohort study (unspecified) & $2(6)$ \\
Mixed retrospective/prospective cohort study & $1(3)$ \\
Before and after study & $6(17)$ \\
& \\
Outcomes reported* & \\
PTB/preterm labour & $6(17)$ \\
Infant mortality & $32(89)$ \\
Congenital anomalies & $5(14)$ \\
\hline
\end{tabular}

*Not mutually exclusive.

during the evaluation which may have affected the outcome.

\section{b) Programmes providing enhanced antenatal care to socioeconomically disadvantaged women with additional clinical risk factors for PTB/LBW}

A cluster randomized trial of the West Los Angeles Preterm Prevention Project [48], a broad, multi-faceted PTB prevention programme, reported a statistically significant reduction in $\mathrm{PTB}$, based on a one-sided test for an intervention effect (7.4\% PTB in the intervention clinics vs. $9.1 \%$ in the control clinics, $\mathrm{p}=.063$ (two-sided), $\mathrm{p}=$ .045 (one-sided); adjusted odds ratio 0.78, two-sided $95 \%$ CI 0.58-1.04). Because the effect was of borderline statistical significance and there were concerns about aspects of the statistical methods (see additional file 3), findings were considered inconclusive by the reviewers but consistent with a possible beneficial effect of the intervention on PTB.

An RCT of an augmented antenatal programme in Alabama [43] reported a non-significant reduction in PTB (10.6\% PTB vs. 14\%, p = 0.22). Findings were considered inconclusive. c) Programmes targeting other vulnerable/at risk groups An observational evaluation of the New York Prenatal Care Assistance Program (PCAP) in HIV positive women [55] reported a significant effect on PTB ( $<37$ weeks) in HIV positive women attending a PCAPaccredited clinic compared with those who received care in a non PCAP-participating clinic (adjusted odds ratio 0.53, 95\% CI 0.40-0.70).

A second overlapping observational evaluation of the same programme in HIV positive substance users [38] reported a significant effect on PTB ( $<37$ weeks) compared with HIV positive substance users who received care in a non-PCAP participating clinic (adjusted odds ratio $0.57,95 \%$ CI 0.34-0.97).

In both cases, the reviewers considered that the evidence was inconclusive due to the risk of selection bias in these non-randomised studies but consistent with a possible beneficial effect of PCAP on PTB in both the populations studied.

\section{Programmes provided as an adjunct to comprehensive antenatal care \\ Results of the seven studies of adequate quality which evaluated interventions provided as an adjunct to stan- dard antenatal care are summarised in Table 6. \\ a) Interventions aimed at socioeconomically disadvantaged women}

Three studies evaluated programmes aimed at socioeconomically disadvantaged women in general: two evaluated home visiting programmes and one evaluated maternity care coordination.

A cluster RCT evaluating the antenatal component of a home visiting programme with a focus on nutritional education, delivered to an isolated rural population (Florina) in Northern Greece [42], reported a significant effect on PTB (3.7\% PTB in the intervention group vs. $8.3 \%$ in the comparator group, $\mathrm{p}<0.04)$. Because the effect was of borderline statistical significance and there were concerns about aspects of the statistical methods (see additional file 3), findings were considered inconclusive but consistent with a possible beneficial effect of the intervention on PTB.

A well-designed RCT to evaluate the antenatal home visiting component of the Prenatal and Early Childhood Nurse Home Visitation Program in multi-disadvantaged, black, low-income women in Tennessee [51], found no evidence of a beneficial effect on PTB (11\% PTB in the intervention group vs. $13 \%$ in the comparator group; adjusted odds ratio 0.8 (95\% CI 0.6-1.2)).

A large retrospective observational evaluation of a maternity care coordination programme provided to Medicaid recipients in North Carolina [23] reported a statistically significant effect on infant mortality (adjusted odds ratio 1.20, 95\% CI 1.47-0.98). Because of 
Table 3 Studies evaluating comprehensive antenatal care programmes

\begin{tabular}{llll}
\hline Study/ Setting & Target population & Study design Intervention
\end{tabular}

Country

Study design

a) Programmes targeting socioeconomically disadvantaged women without specific clinical risk factors for PTB/LBW

Group

antenata

care

Ickovics, Three public antenatal clinics in Atlanta,

Women without severe medical or psychiatric problems

Prospective cohor

2003/USA

Georgia and New Haven, serving

predominantly low-income, uninsured who entered antenatal care at one the three study (Medicaid or self- pay) minority women. 1999 and March 2002 study

Women aged less than 25 entering antenatal care at the Randomised

Publicly funded obstetric clinics in two

Ickovics,

2007/USA and Georgia.

two study sites between September 2001 and controlled Trial December 2004; less than 24 weeks' gestation; risk" medical problems (e.g. HIV); consenting to randomization. Multiple gestations excluded in PTB ‘analysis.

Temple Infant and Parent Support Services (TIPPS) programme

Reece, 2002/ Community and hospital based maternity

Medically indigent women who enrolled in the intensive Prospective cohort maternity care programme(TIPPS) or who enrolled in study usual antenatal care at the study hospital

\section{Tennessee Medicaid Managed Care programme (TennCare)}

Conover, Antenatal services for Medicaid eligible

Women resident in the two study areas delivering a singleton live births in 1993 and 1995. Study

populations NOT restricted to Medicaid eligible women
Before and after study with an

as a control group.

\section{b) Programmes providing enhanced antenatal care to socioeconomically disadvantaged women with additional clinical risk factors for PTB/LBW}

\section{West Los Angeles Preterm Prevention Project}

Hobel, 1994/ Public antenatal clinics in West Los Angeles, Women with a first antenatal clinic visit at one of the USA California. study sites between 1983 and 1986 and with a completed risk assessment indicating high-risk of PTB. Multiple pregnancies, those that aborted at $<20$ weeks gestation and those that resulted in stillbirth or major congenital anomaly excluded.
Cluster randomised Clinic-based enhanced antenatal care for high risk controlled trial women. Eligible women attending the clinics providing the programme receive more frequent visits (every two weeks), pre-term prevention education (three classes covering "identification of pre-term labour, steps to take if signs or symptoms occurred, prevention strategies and what to expect at the hospital") as well as psychosocial. and nutritional screening and crisis intervention. 
Table 3 Studies evaluating comprehensive antenatal care programmes (Continued)

Alabama augmented antenatal care programme for high risk women

Klerman, Public health care system, Jefferson County, African-American, Medicaid- eligible pregnant women 2001/USA Alabama.

seeking antenatal care from the Jefferson County Department of Health between March 1994 and June 1996; women at least 16 yrs old, less than 26 weeks' gestation, with a score of 10 or higher on a risk assessment scale (medical and social factors, including prior PTB, low pre-pregnancy weight, no car for transportation). Women with alcoholism, substance abuse, asthma, cancer, diabetes, epilepsy, high blood pressure, sickle cell disease or HIV/AIDS were excluded.

\section{c) Programmes targeting other vulnerable/at risk groups}

\section{New York Prenatal Care Assistance Program (PCAP)}

Newschaffer, New York State Medicaid antenatal clinics. 1998/USA
HIV infected, drug abusing, Medicaid claimants who delivered a singleton between January 1993 and September 1994.
Randomise controlled Tria

Higher-risk women receive augmented care at a specially created Mother and Family Specialty Center. The programme focuses on informing women about their risk conditions and about what behaviour might improve their pregnancy. The programme includes elements covering smoking cessation,weight gain and vitamin-mineral supplementation and amelioration of psychosocial stress/isolation. Other features include group sessions, regular standing appointments, evening hours where needed, appointment reminders, transportation, and on-site childcare. cohort Study

HIV-infected, New York State Medicaid enrolled women Retrospective delivering a live- born singleton infant between January cohort Study 1993 and October 1995
The programme provides enhanced antenatal care to low income women through a network of accredited hospital clinics. The clinics receive financial incentives to providers to improve basic elements of management and coordination of antenatal care. PCAP accredited clinics must: provide patient outreach to facilitate timely prenatal care; meet frequency and content of care standards set by the American College of Obstetricians and Gynaecologists; conduct comprehensive risk assessment for adverse outcomes; develop prenatal care plans; and provide nutritional services, health education, psychological assessment and HIV related services

involving testing, counselling and management referrals. See above (Newschaffer, 1998) 
Table 4 Studies evaluating programmes provided as an adjunct to comprehensive antenatal care

Study/ Setting Target population $\quad$ Study

design

Intervention

a) Interventions aimed at socioeconomically disadvantaged women

\section{Home visiting}

Kafatos, Rural primary health care clinics in

1991/ Florina, a socioeconomically

Greece disadvantaged rural region in Northern

Women living in a socioeconomically disadvantaged rural area Cluster Greece.

Kublic system of obstetric care

1997/USA Memphis, Tennessee.

\section{Maternity care co-ordination}

Buescher, Services for Medicaid eligible women, Low-income women

Predominantly African- American, low-income women with multiple socio-demographic risk factors (unmarried unemployed and/or less than 12 years education)

1991/USA North Carolina. randomised

controlled

trial

Randomised
controlled
trial

contro
trial

(nu

An outreach health education/counselling service provided by nurses attached to rural primary health clinics. Women receive regular (fortnightly) nurse home visits with an emphasis on nutritional counseling covering food sources and the methods for selecting a balanced diet; instruction in practical techniques to improve the quality of the woman's diet including selection of foods with a high nutrient value and preparation/preservation techniques to reduce the loss of nutrients). Other themes covered during pregnancy included general hygiene, preparation for delivery, breastfeeding and care of the newborn. Home visits continued after delivery until the infant was 12 months old; these visits focused on infant health topics.

A programme based on the 'Elmira'/Family Nurse Partnership model. The antenatal aspect of the interventions (which also includes post natal home visits) involves an average of 7 home visits focusing on improving health-related behaviour (nutrition, smoking, alcohol and illegal drug use). Women are also taught to recognize the signs and symptoms of pregnancy complications and to act appropriately if these occur; and attention is paid to compliance with treatment and to urinary tract infections (UTIs) and sexually transmitted diseases (STDs).

Retrospective The care coordinators help Medicaid-eligible women receive cohort study services and also provide to provide social and emotional support. The programme includes outreach, to help women apply for Medicaid, assessment (psychosocial, nutritional, apply for Medicaid, assessment (psychosocial, nutritional
medical, educational and financial), service planning (development of an individualized plan and provision of assistance to access services), coordination and referral, follow up and monitoring and education and counselling.

b) Interventions aimed at or evaluated in socioeconomically disadvantaged women with additional risk factors for PTB/LBW Home visiting/telephone support

Bryce, Three public hospital antenatal clinics in Women with a prior PTB or other specified risk factors for 1991/ Perth and the offices of 87 obstetricians adverse pregnancy outcome. Intervention not restricted to

Australia and general practitioners in western and gen socioeconomically disadvantaged women but stratified analysis of intervention effect by social class reported

Randomised controlled trial
Higher-risk women receive home visits from midwives at roughly 4-6 weekly intervals (more frequently if requested by the woman) with intervening telephone calls. The midwives provide expressive support ("empathy, understanding, acceptance, ...") and are instructed to provide instrumenta support ("information, advice and material aid") only on request. Physical antenatal care is provided only in an emergency. 


\section{Table 4 Studies evaluating programmes provided as an adjunct to comprehensive antenatal care (Continued)}

Public health clinic, Winston-Salem,

Low-income African- American women and

women with additional risk factors for PTB

Disadvantaged, predominantly 'working class' women with a prior LBW birth.

Randomised controlled

tria

controlled$$
\text { 1990/UK }
$$

\section{c) Interventions evaluated in other vulnerable/at risk groups}

\section{Higgins Nutrition Intervention Program}

Dubois, Subjects recruited from 15 Montreal area Pregnant adolescents

1997/ hospitals but location/setting of the

Canada Montreal Diet Dispensary unclear.
Higher-risk women receive a booklet and additional

instruction about the signs and symptoms of preterm labour

followed by three scheduled nurse phone calls per week. Each

call includes an assessment of health status ("perception of

uterine contractions and other pregnancy changes, color of

urine as an assessment of hydration, number of meals eaten number of cigarettes smoked, alcohol and drug use, and

ingestion of a prenatal vitamin capsule on the previous day"); recommendations based on the assessment; and a discussion

of any additional issues important to the mother

A structured social support intervention consisting of a minimum of three antenatal home visits at 14,20 and 28 weeks, plus two telephone contacts. Midwives engage in semi-structured, open ended discussion with mothers on opics of the mother's choice; the midwives provide advice or (but may refer a mother for care if required)

Retrospective A nutritional programme delivered by trained dieticians as an cohort study adjunct to routine antenatal care. The programme has four elements: assessment of risks for the pregnancy; determination of an individualized "dietary prescription"; teaching of food consumption patterns that meet the individual's requirements while respecting pre-existing food habits; and follow-up and supervision by the same dietician at 2-week intervals. 


\begin{tabular}{|c|c|c|c|c|c|}
\hline & & & & & \\
\hline & & PTB outcome & $\begin{array}{l}\text { Neonatal/infant mortality } \\
\text { outcome }\end{array}$ & PTB & $\begin{array}{l}\text { Neonatal/ } \\
\text { infant } \\
\text { mortality }\end{array}$ \\
\hline \multicolumn{6}{|c|}{ a) Programmes targeting socioeconomically disadvantaged women without specific clinical risk factors for PTB/LBW } \\
\hline \multicolumn{6}{|c|}{ Group antenatal care } \\
\hline $\begin{array}{l}\text { Ickovics, } \\
2003\end{array}$ & $\begin{array}{l}229 \text { antenatal care attendees who volunteered to receive } \\
\text { group antenatal care vs. } 229 \text { antenatal care attendees } \\
\text { selected from the women who did not volunteer to receive } \\
\text { group antenatal care, matched on age, race/ethnicity, parity } \\
\text { and date of delivery. }\end{array}$ & $\begin{array}{l}\text { Unadjusted } \% \text { PTB ( }<37 \text { weeks): } \\
9.2 \% \text { vs. } 9.6 \%, \mathrm{P}=0.83 \text {. } \\
\text { Unadjusted } \% \text { early PTB (<33 weeks): } \\
0.9 \% \text { vs. } 3.1 \% \\
\text { Unadjusted } \% \text { late PTB ( } 33-36.9 \text { weeks): } \\
8.3 \% \text { vs. } 6.5 \%\end{array}$ & $\begin{array}{l}\text { Neonatal deaths, } n(\%) \text { : } \\
0(0 \%) \text { vs. } 3(1.3 \%)\end{array}$ & $\begin{array}{l}\text { Possibly/ } \\
\text { No }\end{array}$ & No/No \\
\hline $\begin{array}{l}\text { Ickovics, } \\
2007\end{array}$ & $\begin{array}{l}625 \text { women randomised to group antenatal care vs. } 370 \\
\text { women randomised to individual antenatal care. }\end{array}$ & $\begin{array}{l}\text { Adjusted \% PTB (<37 weeks): } \\
9.8 \% \text { vs. } 13.8 \%, p=.045 \\
\text { Adjusted odds ratio }(95 \% \text { Cl) for PTB: } \\
0.67 \text { (0.44-0.98) }\end{array}$ & N/A & Yes/Yes & N/A \\
\hline \multicolumn{6}{|c|}{ Temple Infant and Parent Support Services (TIPPS) programme } \\
\hline Reece, 2002 & $\begin{array}{l}380 \text { women enrolled in the Temple Infant and Parent } \\
\text { Support Services (TIPPS) vs. } 437 \text { women (not randomised) } \\
\text { receiving usual care (matched for age, parity, ethnicity, } \\
\text { health insurance and smoking) }\end{array}$ & $\begin{array}{l}\% \mathrm{PTB}^{*}(<37 \text { weeks): } \\
4.3 \% \text { vs. } 12.0 \%, \mathrm{p}<0.005\end{array}$ & N/A & $\begin{array}{l}\text { Yes/ } \\
\text { Possibly }\end{array}$ & N/A \\
\hline \multicolumn{6}{|c|}{ Tennessee Medicaid Managed Care programme (TennCare) } \\
\hline \multirow[t]{2}{*}{$\begin{array}{l}\text { Conover, } \\
2001\end{array}$} & $\begin{array}{l}\text { Before and after study with an adjacent geographical area as } \\
\text { a control group. }\end{array}$ & Adjusted Odds Ratio (95\% CI) for PTB (<37 weeks): & $\begin{array}{l}\text { Adjusted Odds Ratios ( } 95 \% \text { Cl) } \\
\text { for neonatal death ( }<28 \text { days): }\end{array}$ & $\begin{array}{l}\text { No } \\
\text { conclusion } \\
\text { stated/No }\end{array}$ & No/No \\
\hline & $\begin{array}{l}\text { IB = Intervention area, 'before' IA = Intervention area, 'after' } \\
\text { CB = Comparator area, 'before' CA = Comparator area, 'after' } \\
\text { TN = Tennessee NC = North Carolina } \\
\text { Sample size (births): IB: } 69329 \text { IA:70045 CB: } 94012 \text { CA: } 94910 \\
\text { Not randomised. }\end{array}$ & $\begin{array}{l}\text { IB vs. CB: } 0.764(0.74-0.79) \\
\text { IA vs. CA: } 0.796(0.77-0.82) \\
\text { Ratio (IA vs. CA)/(CB vs. CA): } 1.042(1.00-1.09)\end{array}$ & $\begin{array}{l}\text { IB vs. CB: } 0.862(0.74-1.00) \\
\text { IA vs. CA: } 1.012 \text { (0.87-1.18) } \\
\text { Ratio (IA vs. CA)/(IB vs. CB): } \\
1.174 \text { (0.95-1.46) } \\
\text { Adjusted Odds Ratios }(95 \% \text { CI) } \\
\text { for infant death (<1 year): IB vs. } \\
\text { CB (TN vs. NC, 'before'): } 0.990 \\
\text { (0.88-1.11) } \\
\text { IA vs. CA (TN vs. NC, 'after'): } \\
\text { 1.146 (1.02-1.29) } \\
\text { Ratio(IA vs. CA)/(IB vs. CB): } 1.158 \\
(0.98-1.37)\end{array}$ & & \\
\hline
\end{tabular}




\section{Table 5 Effectiveness of comprehensive antenatal care programmes (Continued)}

b) Programmes providing enhanced antenatal care to socioeconomically disadvantaged women with additional clinical risk factors for PTB/LBW

West Los Angeles Preterm Prevention Project

Hobel, 19941774 high-risk women attending a clinic randomised to provide the PTB prevention programme vs. 880 high-risk women attending a clinic randomised to usual care (clinics unaware of women's risk scores).
Unadjusted \% PTB $(<37$ weeks): $7.4 \%$ vs. $9.1 \%(C 1), p=0.063$

Adjusted*Odds Ratio(95\% CI) for PTB(<37 weeks):

N/A

.78 (0.58-1.04). One-sided test for treatment effect: $p=.045$

* Adjusted for number of high risk problems.

Unadjusted \% PTB (undefined):

$10.6 \%$ vs. $14.0 \%, p=0.22$
Yes/

Possibly

No/No

2001

women randomised to usual care

c) Programmes targeting other vulnerable/at risk groups

\section{New York Prenatal Care Assistance Program (PCAP)}

Newschaffer, 240 eligible women (HIV infected, drug abusing) who

$1998 \quad$ received antenatal care at a PCAP participating clinic vs. 113 eligible women who received antenatal care at a non PCAPparticipating clinic

Not randomised

Unadjusted \% PTB $(<37$ weeks):

$3 \%$ vs. $22.6 \%, p=.001$

N/A

Adjusted* Odds Ratio $(95 \%$ Cl) for PTB (<37 weeks):

$0.57(0.34-0.97)$

*Adjusted for maternal characteristics.

Turner, 20001298 eligible women (HIV infected) who received antenatal care from a PCAP- participating clinic vs. 425 eligible women who received antenatal care from a non PCAP- participating clinic.

Not randomised
Adjusted Odds Ratio (95\% C1) for PTB ( $<37$ weeks).

$0.53(0.40-0.70)^{*}$

*Adjusted for maternal characteristic

Additional adjustment for health care and social service use

during pregnancy, illicit drug use, and for adequacy of

antenatal care attenuates the effect, but effects remain

statistically significant. 
a) Interventions aimed at socioeconomically disadvantaged women

Home visiting/telephone support

Kafatos, Florina intervention programme. 296 women attending one of the

Unadjusted \% PTB (<37 weeks):

Neonatal deaths, attending one of the clinics randomised to provide normal care.

Kitzman, 518 women randomised to receive intensive nurse home-visitation

1997 services during pregnancy vs. 681 women randomised to receive normal care during pregnancy.

Unadjusted \% PTB (<37 weeks): $11 \%$ vs. $13 \%$ $n(\%)(<27$ days): Unadjusted \% spontaneous PTB ( $<37$ weeks): N/A

Adjusted Odds Ratio (95\% Cl) for PTB (<37

weeks): 0.8 (0.6-1.2)

Adjusted Odds Ratio (95\% Cl) for

spontaneous PTB (<37 weeks): 0.8 (0.5-1.3)

\section{Maternity care coordination}

Buescher, $\quad 15,526$ women who received maternity care coordination vs, 34,463

1991 women who did not receive maternity care coordination.

Not randomised

Unadjusted infant deaths per 1000 live births: 9.9 vs. 12.2 $\mathrm{p}=0.02$

Adjusted Odds Ratio (95\% Cl) for infant death: $1.20(0.98-1.47)$

\section{/LBW}

b) Interventions aimed at or evaluated in socioeconomically disadvantaged women with additional risk factors for PTB/LB Home visits/telephone support

981 women randomised to receive additional antenatal social support Stratified Odds Ratio (95\% CI) for PTB

1991 vs. 986 women randomised to receive standard antenatal care. (stratified by social class) $0.84(0.65-1.09)$

Odds Ratios by social class: Professiona: $0.59(0.36-0.96)$ Clerical: $1.00(0.64-1.56)$ Manual: 0.96 (0.59-1.56)

Moore, $\quad 775$ women randomised to receive the nurse telephone intervention 1998 vs. 779 women randomised to receive usual care.
\% PTB (<37 weeks)

$9.7 \%$ vs. $11.0 \%$;

Relative Risk (RR) (95\% Cl): 0.87 (0.62-1.22) $p=0.415$

Stratified analysis: Black women, aged $<=$ 18 years: $11.0 \%$ vs. $7.9 \%$ RR: $1.39(0.72,2.67)$, $\mathrm{p}=0.039$

Black women, aged $>=19$ years: $8.7 \%$ vs $15.4 \%$ RR: 0.56 (0.38-0.84), $p=0.004$

White or other women, aged $<=18$ years: White or other women, aged < $=18$ years: $7.8 \%$ Vs. $4.1 \%$ RR. $1.92(0.61-6.02), p=0.255$ White or other women, aged $>=19$ years: $19.6 \%$ vs. $6.6 \%$ RR: 2.99; (0.98-9.09), $p=0.041$

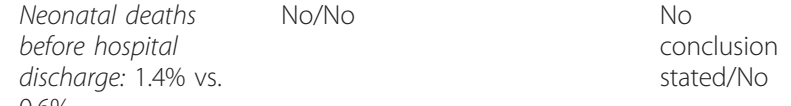

$0.6 \%$

Postneonatal deaths before hospital discharge: $0 \%$ vs. $0.2 \%$ N/A

No*/No *Authors conclude intervention effective in subgroup of black women aged $\geq 19$

(n)




\section{Table 6 Effectiveness of interventions provided as an adjunct to comprehensive antenatal care (Continued)}

\begin{tabular}{|c|c|c|c|c|c|}
\hline $\begin{array}{l}\text { Oakley } \\
1990\end{array}$ & $\begin{array}{l}255 \text { women randomised to receive social support plus usual care vs. } \\
254 \text { women randomised to receive usual care }\end{array}$ & $\begin{array}{l}\% \text { PTB }(<37 \text { weeks): } \\
18 \% \text { vs. } 19 \% \\
\% \text { by gestational age: } \\
<28 \text { weeks: } 2 \% \text { vs. } 1 \% \text { } 28-32 \text { weeks: } 3 \% \text { vs. } \\
4 \% 33-36 \text { weeks: } 13 \% \text { vs. } 14 \% 37+\text { weeks: } \\
82 \% \text { vs. } 81 \%\end{array}$ & $\begin{array}{l}\text { Neonatal deaths (\%): } \\
1 \% \text { vs. } 1 \%\end{array}$ & No conclusion stated/No & $\begin{array}{l}\text { No } \\
\text { conclusion } \\
\text { stated/No }\end{array}$ \\
\hline \multicolumn{6}{|c|}{ c) Interventions evaluated in other vulnerable/at risk groups } \\
\hline \multicolumn{6}{|c|}{ Higgins Nutrition Intervention Program } \\
\hline $\begin{array}{l}\text { Dubois, } \\
1997\end{array}$ & $\begin{array}{l}1203 \text { adolescents who participated in the Higgins Nutrition } \\
\text { Intervention during pregnancy vs. } 1203 \text { adolescents (matched on site, } \\
\text { year and age) who did not receive the intervention. } \\
\text { Not randomized. }\end{array}$ & $\begin{array}{l}\text { Unadjusted \% PTB (<37 weeks): } \\
8.2 \% \text { vs. } 12.8 \% \\
\text { Unadjusted \% very preterm (<34 weeks): } \\
2.3 \% \text { vs. } 5.1 \% \\
\text { Adjusted Odds Ratio }(95 \% \text { CI) for PTB ( }<37 \\
\text { weeks): } \\
0.59 \text { ( } 0.45-0.78), \mathrm{p}<=0.001 \\
\text { Adjusted Odds Ratio }(95 \% \text { CI) for very } \\
\text { preterm birth }(<34 \text { weeks) } \\
0.53 \text { ( } 0.35-0.81), \mathrm{p}<=0.001 \\
\text { Odds ratios also reported for subsamples- } \\
\text { pregravid weight }<50 \mathrm{~kg} \text {; pregravid weight } \\
50 \text { kg or more; } 13-17 \mathrm{yrs} ; 18-19 \text { yrs. }\end{array}$ & N/A & Yes/Possibly & N/A \\
\hline
\end{tabular}


the risk of residual confounding, the reviewers considered the findings inconclusive but consistent with a possible beneficial effect of the intervention on infant mortality.

\section{b) Interventions aimed at or evaluated in socioeconomically} disadvantaged women with additional risk factors for PTB/LBW

Three studies evaluated home visiting/telephone support programmes provided to women with additional risk factors for PTB/LBW.

An RCT of antenatal support delivered through home visits and telephone calls to women with a prior PTB or other risk factors for PTB in Western Australia [46] did not demonstrate a significant beneficial effect on PTB in a socioeconomically mixed population of higher risk women (odds ratio 0.84; 95\% CI 0.65-1.09); a stratified analysis by social class suggested that the beneficial effect, if any, was confined to the most advantaged women in the study. Odds ratios for women classified as 'clerical' and 'manual' were close to one.

An RCT of an intervention involving telephone assessment/advice in North Carolina [52] also found no significant beneficial effect on PTB overall but reported a beneficial effect in a subgroup of black women aged > = 19 years (relative risk 0.56, 95\% CI 0.38-0.84, $\mathrm{p}=0.004$ ). It is unclear if the sub-group analysis by age and ethnicity was pre-specified. The study was not considered to provide evidence of a beneficial effect overall; the subgroup analysis was considered inconclusive but consistent with a possible beneficial effect in black women aged $>=19$.

An RCT of a nurse home visiting programme in the UK, aimed at socioeconomically disadvantaged women with a prior LBW birth [53], similarly found no effect on PTB (18\% PTB in the intervention group vs. 19\% in the usual care arm; odds ratio not reported).

c) Interventions evaluated in other vulnerable/at risk groups An observational evaluation of a nutritional programme, the Higgins Nutrition Intervention Program, in adolescents [41] reported a substantial, statistically significant effect on PTB (<37 weeks) (adjusted odds ratio 0.59, 95\% CI 0.45-0.78) and on early PTB (<34 weeks) (adjusted odds ratio 0.53, 95\% CI 0.35-0.81). Although the study was inconclusive due to the risk of selection bias, the reviewers considered the findings consistent with a possible beneficial effect on PTB.

\section{Discussion}

The purpose of this review was to evaluate the effectiveness of interventions focused on the delivery or organisation of antenatal care as a means of reducing infant mortality or its three major causes (PTB, congenital anomalies, SIDS/SUDI) in disadvantaged and vulnerable women.

We identified 36 primary reports of eligible studies evaluating interventions in a range of disadvantaged and vulnerable populations including socioeconomically disadvantaged/low-income women in general, socioeconomically disadvantaged/low-income women with additional clinical risk factors for adverse pregnancy outcome, and four other specific groups at risk of adverse pregnancy outcome: teenagers, substance users, indigenous women and HIV positive women.

Overall, the quality of evidence was poor and, for most of the interventions considered, there was insufficient evidence to evaluate consistency of findings across multiple studies. Less than half of the included evaluations were considered to have 'adequate' internal validity. Even for interventions shown to be effective in higher quality studies, such as group antenatal care, we considered that the evidence was too sparse to reliably conclude that the interventions were effective in reducing PTB or neonatal mortality in the disadvantaged and vulnerable populations considered, or that the findings could be generalised to other disadvantaged populations.

We concluded that the evidence relating to seven interventions, although inconclusive, indicated a possible beneficial effect on PTB or on infant mortality.

The following four models of comprehensive antenatal care were considered promising:

- Findings of one well-conducted RCT [49] suggested that group antenatal care might reduce PTB in socioeconomically disadvantaged women. A cohort study evaluating the same model of group antenatal care [50] did not show a consistent beneficial effect on PTB, but the study was too small to detect an effect on this outcome. The group antenatal care model is well defined and described and would appear to be transferable to non-US healthcare systems.

- Trials of two broad, multifaceted, clinic-based PTB prevention programmes targeting disadvantaged women with additional clinical risk factors for PTB suggested that such interventions might be effective in reducing PTB. The two interventions evaluated $[43,48]$ were not identical but appeared to share the common approach of targeting a broad range of risk factors in women identified as being at higher-risk. Such programmes would potentially be transferable to non-US healthcare systems, although only one of the two reports provided sufficient detail to enable replication of the main elements of the programme [43].

- The intensive, multi-component TIPPS programme evaluated by Reece [54] was considered promising with regard to possible effects on PTB despite methodological limitations of the evaluation. The TIPPS intervention itself was designed specifically to address the problems and needs of a disadvantaged local population in North Philadelphia and it is unclear 
whether the intervention is transferable or the findings generaliseable to other setting. However, some elements of the intervention and the need-based approach to developing 'locally customised' services may merit further examination and evaluation.

- The two overlapping evaluations of the New York Prenatal Care Assistance Program (PCAP) [38,55] suggested that the PCAP programme might be effective in reducing PTB in HIV positive women, some of whom were drug users. The programme aims to improve outcomes by improving the quality of care through a process of clinic accreditation with financial incentives to 'accredited' providers. The effect of PCAP on other outcomes has also been evaluated in a wider population of socioeconomically disadvantaged women [56]. The use of enhanced payments to providers providing enhanced services is potentially transferable to other healthcare systems but it is unclear whether the specific services covered by PCAP accreditation would be relevant in other settings.

Three interventions provided as an adjunct to standard antenatal care were also considered promising:

- Two nutritional programmes were tentatively considered promising. An evaluation of the Higgins Nutrition Intervention Program in pregnant teenagers indicated a possible beneficial effect on PTB in this population, despite the methodological limitations of the study [41]; and the evaluation of a home visiting programme focussing on nutritional education (the Florina Intervention Program) also suggested a possible beneficial effect on PTB in a low-income rural population in Greece [42,57]. The Florina Intervention Program was evaluated in isolated agricultural population in Greece with a low-calorie, seasonal diet based on home produce and domestic livestock [57]; the relevance and generalisability of the nutritional elements of the intervention to more urbanised populations is unclear.

- A single US-based study indicated that maternity care coordination might have a beneficial effect on infant mortality in socially disadvantaged women in the USA [23]. However, it is unclear to what extent these findings can be generalised to other healthcare systems since some elements of the intervention may be specific to the healthcare and welfare systems in the USA.

Although we identified seven studies evaluating 'teen' clinics, no conclusions could be drawn regarding the effectiveness of such clinics because of problems of study design and selection bias in the included studies.

We found insufficient evidence of adequate quality to draw any conclusions regarding the effectiveness of the other interventions evaluated.

\section{Strengths and limitations of this systematic review}

In line with our aim to identify the best available evidence on antenatal care interventions targeting socially disadvantaged and vulnerable women we did not restrict ourselves to particular study designs and we designed our searches to reflect this breadth of interest. This lack of specificity may be seen as both strength and a weakness of this review.

The inclusion of less methodologically rigorous evaluations increased the volume of material identified and reviewed and also presented methodological challenges with regard to quality assessment. Furthermore, in practice, it did not add greatly to the evidence regarding effectiveness. Nevertheless, the inclusion and systematic quality appraisal of such evaluations may have served the useful function of highlighting the lack of robust evidence supporting the effectiveness of some widely studied interventions, e.g. 'teen' clinics.

The decision to review a broad category of interventionsantenatal care programmes involving the delivery or organisation of antenatal care-rather than identifying specific interventions a priori, has enabled us to provide an overview of a wide range of interventions. A more focussed approach examining a smaller range of specific interventions would have been more consistent with standard systematic reviewing methods, although developing and applying precise interventions definitions-required to ensure reproducible selection of studies-would potentially have been challenging. Furthermore, such an approach would have lacked the flexibility to review a broad, rather diffuse and poorly defined evidence base which was possible with our more comprehensive approach. However, a disadvantage is that a more comprehensive approach necessitates a degree of post hoc decision making [32]. For example, following our initial searches we had to decide how best to classify and group the interventions. It is possible that different ways of classifying and grouping the interventions might have changed the 'weight of evidence' in favour of an intervention within scope of the review, but, given the limitations of the evidence, we think it unlikely that this would have resulted in major changes to our conclusions.

An unanticipated consequence of our 'generic' inclusion/exclusion criteria was the exclusion of some seemingly relevant interventions provided as an 'add on' to normal antenatal care. For example, studies relating to some welfare-based US programmes (such as the Special Supplemental Food Program for Women, Infants and Children (WIC)) were excluded not because the intervention was ineligible but because studies evaluating the intervention typically compared 'intervention recipients' with 'non-recipients', with the latter group including women who received no antenatal care. The studies were therefore excluded because they lacked a comparator group receiving standard antenatal care. 
It is possible that we may have missed some relevant 'add on' interventions as a result of using non-specific antenatal care search terms (e.g. 'prenatal care') instead of more intervention specific terms. Similarly, socioeconomically disadvantaged study populations are not consistently indexed or mentioned in searchable elements of the bibliographic record. We took some additional steps to increase ascertainment of relevant material, including using an adapted version of an 'equity filter' (developed by the EPPI-Centre to identify material relating to health inequalities) in our searches, and 'snowballing' [58].

Although the titles of articles lacking an abstract were screened and the full-text retrieved where appropriate, there is the possibility that relevant studies lacking an abstract may have been missed; non-English language articles lacking an English abstract were not included.

\section{Findings in relation to other published evidence}

One previous review conducted in the early $1990 \mathrm{~s}$ sought to evaluate the "best" evidence relating to the effect of antenatal healthcare programmes on pregnancy outcomes, including infant mortality and gestational age at birth [21]. The authors concluded that maternal care coordination, home visits by nurses and specially targeted smoking and nutritional programmes were associated with "optimized pregnancy outcomes for certain groups of women, including the poor and very young." Nevertheless, as in the present review, and for similar reasons, they urged caution in applying these findings.

Other published reviews have addressed the effectiveness of a range of specific antenatal care interventions but most without a focus on effectiveness in disadvantaged or vulnerable groups of pregnant women:

- PTB prevention educational programmes for high risk women $\mathrm{A}$ systematic review and metaanalysis of RCTs of PTB prevention educational programmes [59] concluded that they appeared to have little benefit in reducing PTB and might result in an increased rate of diagnosis of preterm labour.

- Home visiting programmes A review of the effect of home visits on a range of pregnancy outcomes including PTB (<37 weeks) [26] found that home visiting programmes in general, and more specific programmes (those providing social support and those providing medical care to women with complications) did not improve the preterm delivery rate or other pregnancy outcomes. A second review of interventions involving support during pregnancy for women at increased risk of LBW babies [60], found no effect on PTB (Risk ratio 0.92 , 95\% CI 0.83 - 1.01). A further 'review of reviews' [61] similarly concluded that there was insufficient evidence to suggest that home-visiting programmes had a beneficial impact on low birth weight or other pregnancy outcomes.

- Telephone support A recent review of telephone support interventions concluded that they were ineffective at reducing PTB [25].

- Nutritional interventions A review of the effectiveness of interventions to optimize gestational weight gain and diet in pregnant adolescents [62] concluded that such interventions had achieved "promising results" with regard to a range of pregnancy outcomes but found little evidence relating to effects on PTB. The review did not systematically assess the quality of the included material but noted that much of the evidence was methodologically flawed. A further review assessed the effects of a range of nutritional interventions during pregnancy, including advice to increase or reduce energy or protein intake [63]. The authors concluded that although dietary advice appeared to be effective in increasing pregnant women's energy and protein intakes it was unlikely to confer major benefits on infant or maternal health. These findings do not support our tentative conclusions regarding the potentially 'promising' effect of the two programmes with a nutritional focus included in the present review (the Higgins nutritional intervention in teenagers [41], and the Florina home visiting programme which has a nutritional counselling focus [42]) and, on balance, may suggest that a more cautious interpretation of the evidence in favour of these two interventions would be warranted.

- Midwife-led antenatal care A Cochrane review [64] did not find a significant beneficial effect of midwifeled antenatal care on PTB compared with other models of care (risk ratio $0.87,95 \%$ CI 0.73-1.04). A second overlapping review of continuity of midwifery care vs. standard care [28] additionally found no significant effect on neonatal mortality (odds ratio 1.27, 95\% CI $0.49-3.34)$. A third review examined the evidence relating to various aspects of antenatal care for low-risk women including the effectiveness of midwife/general practitioner-managed care vs. obstetrician/gynaecologist-led shared care [30] also found no significant effect on PTB (relative risk 0.80, 95\% CI 0.59 - 1.10).

- Antenatal care targeting specific vulnerable groups Rumbold and Cunningham reviewed the impact of antenatal care interventions on Australian indigenous women [24]. They did not assess the quality of the included studies so the interpretation of their findings is uncertain.

With the exception of the findings relating to the possible ineffectiveness of nutritional interventions noted above, the findings of other published reviews appear consistent with 
our assessment of the effectiveness of antenatal care programmes in disadvantaged and vulnerable populations.

\section{Conclusions}

In summary, we found insufficient evidence of adequate quality to conclude that interventions involving alternative models of organising or delivering antenatal care have been demonstrated to be effective in reducing infant mortality or PTB in socially disadvantaged or vulnerable populations compared with standard models of antenatal care. A small number of the interventions reviewed here were considered 'promising' in terms of their effect on PTB in socially disadvantaged or vulnerable populations, but the effects, if any, are likely to be modest and further robust evaluation would be required before routine adoption of these interventions could be recommended.

\section{Additional material}

Additional file 1: Details of the search strategies used in the review.
Additional file 2: Reasons for exclusion during screening.
Additional file 3: Study quality: results of GATE assessment.
Additional file 4: Overview of the intervention characteristics, by
target population.

\section{List of abbreviations}

OECD: Organisation for Economic Co-operation and Development; WIC Special Supplemental Nutrition Program for Women, Infants and Children.

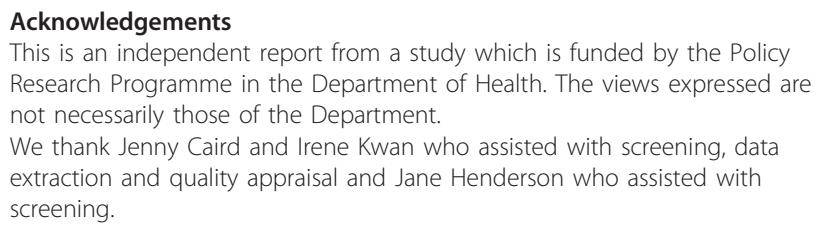

\section{Authors' contributions}

$J H, J K, P B$ and RG were involved in study concept and design; JH and RG developed the search strategy; JH ran the searches, carried out screening, quality appraisal and data extraction with the assistance of LO and other members of the review team (see acknowledgements); JK and RG assisted with full-text screening and quality appraisal in cases of disagreement between reviewers; JH wrote the study report and drafted the manuscript; all authors were involved in review and approval of the final manuscript.

\section{Competing interests}

The authors declare that they have no competing interests.

Received: 25 November 2010 Accepted: 11 February 2011 Published: 11 February 2011

\section{References}

1. World bank data catalogue. [http://data.worldbank.org/data-catalog/worlddevelopment-indicators].

2. Norman PP, Gregory IP, Dorling DD, Baker AA: Geographical trends in infant mortality: England and Wales, 1970-2006. Health Statistics Quarterly 2008, 40:18-29.

3. Arntzen A, Andersen AMN: Social determinants for infant mortality in the Nordic countries, 1980 - 2001. Scandinavian Journal of Public Health 2004, 32(5):381-389.
4. Luo Z-C, Wilkins R, Kramer MS, for the F Infant Health Study Group of the Canadian Perinatal Surveillance S: Effect of neighbourhood income and maternal education on birth outcomes: a population-based study. CMAJ 2006, 174(10):1415-1420.

5. Kurinczuk JJ, Hollowell J, Brocklehurst P, Gray G: Inequalities in infant mortality project briefing paper 1 . Infant mortality: overview and context. Oxford: National Perinatal Epidemiology Unit; 2009 [https://www.npeu.ox.ac. uk/files/downloads/infant-mortality/Infant-Mortality-Briefing-Paper-1.pdf].

6. Callaghan WM, MacDorman MF, Rasmussen SA, Qin C, Lackritz EM: The Contribution of Preterm Birth to Infant Mortality Rates in the United States. Pediatrics 2006, 118(4):1566-1573.

7. Rosano A, Botto LD, Botting B, Mastroiacovo P: Infant mortality and congenital anomalies from 1950 to 1994: an international perspective. Journal of Epidemiology and Community Health 2000, 54(9):660-666.

8. Gray R, Bonellie SR, Chalmers J, Greer I, Jarvis S, Williams C: Social inequalities in preterm birth in Scotland 1980-2003: findings from an area-based measure of deprivation. BJOG 2008, 115(1):82-90.

9. Vrijheid M, Dolk H, Stone D, Abramsky L, Alberman E, Scott JES: Socioeconomic inequalities in risk of congenital anomaly. Arch Dis Child 2000, 82(5):349-352.

10. Oakley L, Maconochie N, Doyle P, Dattani N, Moser K: Multivariate analysis of infant death in England and Wales in 2005-06, with focus on socioeconomic status and deprivation. Health Statistics Quarterly 2009, 42(1):22-39.

11. Gray R, Headley J, Oakley L, Kurinczuk JJ, Brocklehurst P, Hollowell J: Inequalities in infant mortality project briefing paper 3 . Towards an understanding of variations in infant mortality rates between different ethnic groups in England \& Wales. Oxford: National Perinatal Epidemiology Unit; 2009 [https://www.npeu.ox.ac.uk/files/downloads/infantmortality/Infant-Mortality-Briefing-Paper-3.pdf].

12. D'Souza L, Garcia J: Improving services for disadvantaged childbearing women. Child Care Health Dev 2004, 30(6):599-611.

13. Little M, Shah R, Vermeulen MJ, Gorman A, Dzendoletas D, Ray JG: Adverse perinatal outcomes associated with homelessness and substance use in pregnancy. CMAJ 2005, 173(6):615-618.

14. Knight $M$, Plugge E: Risk factors for adverse perinatal outcomes in imprisoned pregnant women: a systematic review. BMC Public Health 2005, 5(1):111.

15. Boy A, Salihu AM: Intimate partner violence and birth outcomes: A systematic review. Int J Fertil Womens Med 2004, 49(4):159-164.

16. King-Hele S, Webb RT, Mortensen PB, Appleby L, Pickles A, Abel KM: Risk of stillbirth and neonatal death linked with maternal mental illness: a national cohort study. Arch Dis Child Fetal Neonatal Ed 2009, 94(2): F105-110.

17. Ludlow JP, Evans SF, Hulse G: Obstetric and perinatal outcomes in pregnancies associated with illicit substance abuse. Australian and New Zealand Journal of Obstetrics and Gynaecology 2004, 44(4):302-306.

18. Hulse GK, Milne E, English DR, Holman CDJ: The relationship between maternal use of heroin and methadone and infant birth weight. Addiction 1997, 92(11):1571-1579.

19. Hollowell J, Allen F, Gray R, Oakley L, Kurinczuk JJ, Brocklehurst P: Inequalities in infant Mortality Project Evidence Map report 1. Interventions targeting infant mortality: a user's guide to the systematic review evidence. Oxford: National Perinatal Epidemiology Unit; 2009 [https://www.npeu.ox.ac.uk/files/downloads/infant-mortality/Infant-MortalityUser-Guide.pdf].

20. Villar J, Bergsjo P: Scientific basis for the content of routine antenatal care I. Philosophy, recent studies, and power to eliminate or alleviate adverse maternal outcomes. Acta Obstetricia et Gynecologica Scandinavica 1997, 76(1):1-14.

21. Fink A, Yano EM, Goya D: Prenatal programs: what the literature reveals. Obstet Gynecol 1992, 80(5):867-872.

22. Olds DL, Henderson CR Jr, Tatelbaum R, Chamberlin R: Improving the Delivery of Prenatal Care and Outcomes of Pregnancy: A Randomized Trial of Nurse Home Visitation. Pediatrics 1986, 77(1):16-28.

23. Buescher PA, Roth MS, Williams D, Goforth CM: An evaluation of the impact of maternity care coordination on Medicaid birth outcomes in North Carolina. American Journal of Public Health 1991, 81(12):1625-1629.

24. Rumbold AR, Cunningham J: A review of the impact of antenatal care for Australian Indigenous women and attempts to strengthen these services. Maternal and Child Health Journal 2008, 12(1):83-100. 
25. Dennis C-L, Kingston D: A Systematic Review of Telephone Support for Women During Pregnancy and the Early Postpartum Period. J Obstet Gynecol Neonatal Nurs 2008, 37(3):301-314.

26. Blondel B, Bréart G: Home visits during pregnancy: Consequences on pregnancy outcome, use of health services, and women's situations. Seminars in Perinatology 1995, 19(4):263-271.

27. Hodnett ED: Continuity of caregivers for care during pregnancy and childbirth. Cochrane Database Syst Rev 2000, 1.

28. Waldenstrom U, Turnbull D: A systematic review comparing continuity of midwifery care with standard maternity services. Br J Obstet Gynaecol 1998, 105(11):1160-1170.

29. Carroli G, Villar J, Piaggio G, Khan-Neelofur D, Gulmezoglu M, Mugford M, Lumbiganon P, Farnot U, Bersgjo P: WHO systematic review of randomised controlled trials of routine antenatal care. Lancet 2001, 357(9268):1565-1570.

30. Khan-Neelofur D, Gulmezoglu M, Villar J: Who should provide routine antenatal care for low-risk women, and how often? A systematic review of randomised controlled trials. Paediatric and Perinatal Epidemiology 1998, 12(Suppl 2):7-26.

31. Dowswell T, Carroli G, Duley L, Gates S, Gülmezoglu AM, Khan-Neelofur D, Piaggio Gilda GP: Alternative versus standard packages of antenatal care for low-risk pregnancy. Cochrane Database Syst Rev 2010, 10.

32. Lomas J: Using research to inform healthcare managers' and policy makers' questions: from summative to interpretive synthesis. Healthcare Policy 2005, 1(1):55.

33. Jackson R, Ameratunga S, Broad J, Connor J, Lethaby A, Robb G, Wells S, Glasziou P, Heneghan C: The GATE frame: critical appraisal with pictures. Evid Based Med 2006, 11(2):35-38.

34. National Institute for Health and Clinical Excellence: Methods for the development of NICE public health guidance. London, second 2009.

35. Thomas J: Information systems for conducting systematic reviews: a case study. Sixth International Campbell Colloquium. Los Angeles, 22-24 February 2006 [http://eppi.ioe.ac.uk/cms/], Poster.

36. Panaretto KS, Lee HM, Mitchell MR, Larkins SL, Manessis V, Buettner PG, Watson D: Impact of a collaborative shared antenatal care program for urban Indigenous women: a prospective cohort study. Medical Journal of Australia 2005, 182(10):514-519.

37. Muender MM, Moore ML, Chen GJ, Sevick MA: Cost-benefit of a nursing telephone intervention to reduce preterm and low-birthweight births in an African American clinic population. Prev Med 2000, 30(4):271-276.

38. Newschaffer CJ, Cocroft J, Hauck WW, Fanning T, Turner BJ: Improved birth outcomes associated with enhanced Medicaid prenatal care in drugusing women infected with the human immunodeficiency virus. Obstetrics and Gynecology 1998, 91(6):885-891.

39. Goldenberg RL, Davis RO, Copper RL, Corliss DK, Andrews JB, Carpenter AH: The Alabama preterm birth prevention project. Obstetrics and Gynecology 1990, 75(6):933-939.

40. Burkett G, Gomez-Marin O, Yasin SY, Martinez M: Prenatal care in cocaineexposed pregnancies. Obstetrics and Gynecology 1998, 92(2):193-200.

41. Dubois S, Coulombe C, Pencharz P, Pinsonneault O, Duquette MP: Ability of the Higgins Nutrition Intervention Program to improve adolescent pregnancy outcome. Journal of the American Dietetic Association 1997, 97(8):871-878.

42. Kafatos AG, Tsitoura S, Pantelakis SN, Doxiadis SA: Maternal and infant health education in a rural Greek community. Hygie 1991, 10(1):32-37.

43. Klerman LV, Ramey SL, Goldenberg RL, Marbury S, Hou J, Cliver SP: A randomized trial of augmented prenatal care for multiple-risk, Medicaideligible African American women. American Journal of Public Health 2001, 91(1):105-111.

44. Miles J, Sugumar K, Macrory F, Sims DG, D'Souza SW: Methadone-exposed newborn infants: Outcome after alterations to a service for mothers and infants. Child: Care, Health and Development 2007, 33(2):206-212.

45. Van Winter JT, Harmon MC, Atkinson EJ, Simmons PS, Ogburn PL Jr: Young moms' clinic: A multidisciplinary approach to pregnancy education in teens and in young single women. Journal of Pediatric and Adolescent Gynecology 1997, 10(1):28-33.

46. Bryce RL, Stanley FJ, Garner JB: Randomized controlled trial of antenatal social support to prevent preterm birth. British Journal of Obstetrics and Gynaecology 1991, 98(10):1001-1008.

47. Conover CJ, Rankin PJ, Sloan FA: Effects of Tennessee Medicaid managed care on obstetrical care and birth outcomes. J Health Polit Policy Law 2001, 26(6):1291-1324.
48. Hobel CJ, Ross MG, Bemis RL, Bragonier JR, Nessim S, Sandhu M, Bear MB, Mori B: The West Los Angeles Preterm Birth Prevention Project. I. Program impact on high-risk women. Am J Obstet Gynecol 1994, 170(1 Pt 1):54-62.

49. Ickovics JR, Kershaw TS, Westdahl C, Magriples U, Massey Z, Reynolds H, Rising SS: Group prenatal care and perinatal outcomes: a randomized controlled trial. Obstet Gynecol 2007, 110(2 Pt 1):330-339.

50. Ickovics JR, Kershaw TS, Westdahl C, Rising SS, Klima C, Reynolds H, Magriples U: Group prenatal care and preterm birth weight: Results from a matched cohort study at public clinics. Obstetrics and Gynecology 2003, 102(5):1051-1057.

51. Kitzman H, Olds DL, Henderson CR, Hanks C, Cole R, Tatelbaum R McConnochie KM, Sidora K, Luckey DW, Shaver D, et al: Effect of prenatal and infancy home visitation by nurses on pregnancy outcomes, childhood injuries, and repeated childbearing. A randomized controlled trial. JAMA 1997, 278(8):644-652 [http://jama.ama-assn.org/content/278/8/ 644.abstract].

52. Moore ML, Meis PJ, Ernest JM, Wells HB, Zaccaro DJ, Terrell T: A randomized trial of nurse intervention to reduce preterm and low birth weight births. Obstetrics and Gynecology 1998, 91 (5 Pt 1):656-661.

53. Oakley A, Rajan L, Grant A: Social support and pregnancy outcome. $\mathrm{Br} J$ Obstet Gynaecol 1990, 97(2):155-162.

54. Reece EA, Leguizamon G, Silva J, Whiteman V, Smith D: Intensive interventional maternity care reduces infant morbidity and hospital costs. J Matern Fetal Neonatal Med 2002, 11(3):204-210.

55. Turner BJ, Newschaffer CJ, Cocroft J, Fanning TR, Marcus S, Hauck WW: Improved birth outcomes among HIV-infected women with enhanced medicaid prenatal care. American Journal of Public Health 2000, 90(1):85-91.

56. Joyce T: Impact of augmented prenatal care on birth outcomes of Medicaid recipients in New York City. Journal of Health Economics 1999, 18(1):31-67.

57. Kafatos $A G$, Vlachonikolis IG, Codrington CA: Nutrition during pregnancy: the effects of an educational intervention program in Greece. Am J Clin Nutr 1989, 50(5):970-979.

58. Greenhalgh T, Peacock R: Effectiveness and efficiency of search methods in systematic reviews of complex evidence: audit of primary sources. BMJ 2005, 331(7524):1064-1065.

59. Hueston WJ, Knox MA, Eilers G, Pauwels J, Lonsdorf D: The effectiveness of preterm-birth prevention educational programs for high-risk women: a meta-analysis. Obstetrics and Gynecology 1995, 86:705.

60. Hodnett ED, Fredericks S, Weston J: Support during pregnancy for women at increased risk of low birthweight babies. Cochrane Database Syst Rev 2010, 6 .

61. Bull J, McCormick G, Swann C, Mulvihill C: Ante- and post-natal homevisiting programmes: a review of reviews. Evidence briefing. London: Health Development Agency; 2004.

62. Nielsen JN, Gittelsohn JJ, Anliker JJ, O'Brien KK: Interventions to improve diet and weight gain among pregnant adolescents and recommendations for future research. Journal of the American Dietetic Association 2006, 106(11):1825-1840.

63. Kramer MS, Kakuma R: Energy and protein intake in pregnancy. Cochrane Database Syst Rev 2003, 4.

64. Hatem M, Sandall J, Devane D, Soltani H, Gates S: Midwife-led versus other models of care for childbearing women. Cochrane Database Syst Rev 2008, 4.

65. Clarke LL, Miller MK, Vogel WB, Davis KE, Mahan CS: The effectiveness of Florida's "Improved Pregnancy Outcome" program. J Health Care Poor Underserved 1993, 4(2):117-132.

66. Lenaway D, Koepsell TD, Vaughan T, van Belle G, Shy K, Cruz-Uribe F: Evaluation of a public-private certified nurse-midwife maternity program for indigent women. American Journal of Public Health 1998 88(4):675-679.

67. Mvula MM, Miller JM Jr: A comparative evaluation of collaborative prenatal care. Obstetrics and Gynecology 1998, 91(2):169-173.

68. Collaborative Group on Preterm Birth Prevention: Multicenter randomized, controlled trial of a preterm birth prevention program. Am J Obstet Gynecol 1993, 169(2 Pt 1):352-366.

69. Bienstock JL, Ural SH, Blakemore K, Pressman EK: University hospital-based prenatal care decreases the rate of preterm delivery and costs, when compared to managed care. Journal of Maternal-Fetal Medicine 2001, 10(2):127-130. 
70. Edwards CF, Chazotte C, Freda MC, Shah L, Girz B, Damus K, Merkatz IR: Impact of an inner-city, hospital-based preterm prevention program on preterm births in twin gestation. Journal of the Association for Academic Minority Physicians 1995, 6(2):78-81.

71. Bensussen-Walls W, Saewyc EM: Teen-focused care versus adult-focused care for the high-risk pregnant adolescent: an outcomes evaluation. Public Health Nursing 2001, 18(6):424-435.

72. Das S, Dhulkotia JS, Brook J, Amu O: The impact of a dedicated antenatal clinic on the obstetric and neonatal outcomes in adolescent pregnant women. Journal of Obstetrics and Gynaecology 2007, 27(5):464-466.

73. Morris DL, Berenson AB, Lawson J, Wiemann CM: Comparison of adolescent pregnancy outcomes by prenatal care source. Journal of Reproductive Medicine for the Obstetrician and Gynecologist 1993, 38(5):375-380

74. Perez R, Patience T, Pulous E, Brown G, McEwen A, Asato A, Hume R, Calhoun BC: Use of a focussed teen prenatal clinic at a military teaching hospital: Model for improved outcomes of unmarried mothers. Australian and New Zealand Journal of Obstetrics and Gynaecology 1998, 38(3):280-283.

75. Quinlivan JA, Evans SF: Teenage antenatal clinics may reduce the rate of preterm birth: A prospective study. BJOG: An International Journal of Obstetrics and Gynaecology 2004, 111(6):571-578.

76. Ukil D, Esen UI: Early teenage pregnancy outcome: a comparison between a standard and a dedicated teenage antenatal clinic. Journal of Obstetrics and Gynaecology 2002, 22(3):270-272.

77. Grady MA, Bloom KC: Pregnancy outcomes of adolescents enrolled in a CenteringPregnancy program. J Midwifery Womens Health 2004, 49(5):412-420 [http://onlinelibrary.wiley.com/doi/10.1111/j.1542-2011.2004. tb04435.x/abstract]

78. Mackerras D: Birthweight changes in the pilot phase of the Strong Women Strong Babies Strong Culture program in the Northern Territory. Australian and New Zealand Journal of Public Health 2001, 25(1):34-40.

79. Panaretto KS, Mitchell MR, Anderson L, Larkins SL, Manessis V, Buettner PG Watson D: Sustainable antenatal care services in an urban Indigenous community: the Townsville experience. The Medical Journal of Australia 2007, 187(1):18-22.

80. Keeton K, Saunders SE, Koltun D: The effect of the Family Case Management Program on 1996 birth outcomes in Illinois. J Womens Health (Larchmt) 2004, 13(2):207-215.

81. Lane SD, Cibula DA, Milano LP, Shaw M, Bourgeois B, Schweitzer F, Steiner C, Dygert K, DeMott K, Wilson K, et al: Racial and ethnic disparities in infant mortality: risk in social context. J Public Health Manag Pract 2001, 7(3):30-46 [http://journals.Iww.com/jphmp/Abstract/2001/07030/ Racial_and_Ethnic_Disparities_in_Infant_Mortality_.7.aspx].

82. Armstrong MA, Gonzales Osejo V, Lieberman L, Carpenter DM, Pantoja PM, Escobar GJ: Perinatal substance abuse intervention in obstetric clinics decreases adverse neonatal outcomes. Journal of Perinatology 2003, 23(1):3-9.

83. Sweeney PJ, Schwartz RM, Mattis NG, Vohr B: The effect of integrating substance abuse treatment with prenatal care on birth outcome. Journal of Perinatology 2000, 20(4):219-224.

\section{Pre-publication history}

The pre-publication history for this paper can be accessed here: http://www.biomedcentral.com/1471-2393/11/13/prepub

doi:10.1186/1471-2393-11-13

Cite this article as: Hollowell et al:: The effectiveness of antenatal care programmes to reduce infant mortality and preterm birth in socially disadvantaged and vulnerable women in high-income countries: a systematic review. BMC Pregnancy and Childbirth 2011 11:13.

\section{Submit your next manuscript to BioMed Central and take full advantage of:}

- Convenient online submission

- Thorough peer review

- No space constraints or color figure charges

- Immediate publication on acceptance

- Inclusion in PubMed, CAS, Scopus and Google Scholar

- Research which is freely available for redistribution

Submit your manuscript at www.biomedcentral.com/submit
C) Biomed Central 